\title{
STUDY OF INDICATIONS OF BLOOD COMPONENTS IN OBSTETRIC HEMORRHAGE AT A TERTIARY CARE CENTRE IN SOUTH INDIA
}

\section{Dr. Sushama D* \\ Dr. Kumari K.C. Usha}

Assistant Professor; Department of Transfusion Medicine, Government Medical College, Thrissur, Kerala. *Corresponding Author

Former Professor and Head; Department of Transfusion Medicine, Government Medical College, Trivandrum, Kerala

\section{Dr. Anumole Jose}

Assistant Surgeon, Kerala Health Services.

ABSTRACT Blood transfusion is an essential part of management of many indications in obstetrics. A prospective study was conducted with objectives to portray the indications, mean usage and inter-relationship of blood components in obstetric hemorrhages. Out of total 10063 obstetric patients, 405 patients (N) required transfusion (4.02\% incidence). Detailed clinical and transfusion history and management was recorded and analyzed. A total of 1386 units (55\% packed red cells, $19 \%$ platelet concentrates, $24 \%$ fresh frozen plasma and $2 \%$ cryoprecipitate) of blood components were used to treat obstetric hemorrhage cases. Most common indication for blood transfusion was observed to be uterine atony (37\%) followed by abruption (18.5\%) and genital tract trauma during delivery (14.8\%) and other causes. A strong positive correlation of PRC usage was observed with the number of units (usage) of PC, FFP and Cryoprecipitate units transfused to the patients with obstetric hemorrhage $(\mathrm{P}<0.00001 ; \mathrm{P}<0.00001$ and $\mathrm{P}=0.002786$ respectively). Most common indication for transfusion of blood components was uterine atony. Maximum mean usages of packed red cells, platelet concentrate and fresh frozen plasma were for placenta accreta/percreta/increta.

KEYWORDS : Obstetric hemorrhage, blood transfusion, packed red cells, platelet concentrate, fresh frozen plasma

\section{INTRODUCTION}

Blood transfusion was recognized as one of the eight essential components of Comprehensive Emergency Obstetric Care (cEmOC). This had been shown to reduce the rates of maternal mortality. ${ }^{[1,2]}$

In the available medical literature there was a paucity of studies that focus on transfusion practice in obstetric hemorrhage as a life saving measure. Thus, the present study was conducted with objectives to describe the indications, mean usage and inter-relationship of blood components in obstetric hemorrhages.

A better understanding of prevalence of blood transfusions in the management of obstetric hemorrhage, various indications or requirements of different blood components can help achieving optimum usage of blood and its different components.

\section{MATERIAL AND METHODS}

This was a prospective study, conducted on subjects with obstetric hemorrhage requiring blood / blood component transfusions, admitted under the department of Obstetrics and Gynecology. Study was approved by the Human Ethics Committee and Institutional Review Board (IEC No. 02/ 33/ 2014/MCT/14-02-2014) and was undertaken over a period of 12 months from 14-02-2014 to 13-02-2015 in the Department of Transfusion Medicine in collaboration with Department of Obstetrics and Gynecology at our institute.

Subjects were counseled about the nature and effects of the study and a written consent was obtained from them or next of kin in case of unconscious patient.

Detailed clinical and transfusion history along with proportion of uterine atony, genital tract trauma including uterine rupture/injury, abruption, placenta previa and placenta accrete were recorded.

All the data was analyzed statistically using SPSS software version 16. Continuous variables were expressed as mean \pm standard deviation and qualitative data was expressed as frequencies and percentages in the form of tables and charts as required. Pearson's correlation test was applied to assess relationship of packed red cells (PRC) usage with other blood components. $\mathrm{P}$ value of less than 5 percent was considered statistically significant.

\section{RESULTS}

Total number of obstetric cases admitted in our tertiary care centre during the study period was 10063 out of which 405 patients required transfusion of blood component for management of obstetric hemorrhage. Incidence of blood or blood component transfusion was $4.02 \%$. Mean age of the study population was $26.3 \pm 5.18$ years. Most of the subjects were having the gestational age between 36-40 weeks (61.5\%). Median gestational age of the subjects was 37(5-40) weeks.

Only allogenic transfusions were performed in the study subjects. A total of 1386 units of blood components were used to treat obstetric hemorrhage. This constituted $55 \%$ (762) of packed red cells, $19 \%$ (258) of platelet concentrates, $24 \%$ (339) of fresh frozen plasma and $2 \%$ (27) of cryoprecipitate.

Among the transfused cases, $72.6 \%$ received packed red cells alone, 1.5\% FFP alone and rest of the subjects received combination of blood components.

TABLE - 1 USAGE OF PACKED RED CELLS FOR VARIOUS INDICATIONS RELATED TO OBSTETRIC HEMORRHAGE

\begin{tabular}{|c|c|c|c|c|c|c|c|c|}
\hline 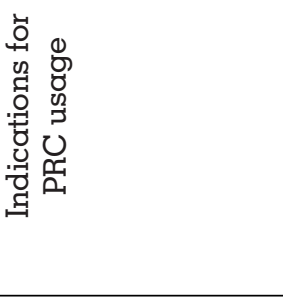 & z & 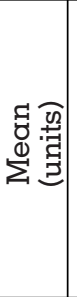 & 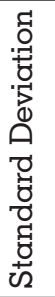 & 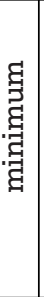 & 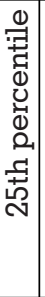 & 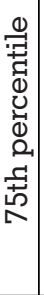 & 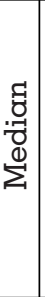 & 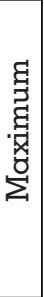 \\
\hline Abortion & 15 & 1.6 & 0.8 & 1 & 1 & 1 & 2 & 3 \\
\hline Ruptured Ectopic & 27 & 1.6 & 0.7 & 1 & 1 & 1 & 2 & 3 \\
\hline GTN / V Mole & 3 & 3.0 & 0.0 & 3 & 3 & 3 & 3 & 3 \\
\hline Abruption & 75 & 1.8 & 1.0 & 1 & 1 & 2 & 2 & 5 \\
\hline Placenta previa & 39 & 1.2 & 0.4 & 1 & 1 & 1 & 1 & 2 \\
\hline
\end{tabular}




\begin{tabular}{|c|c|c|c|c|c|c|c|c|}
\hline Atonicity & 150 & 1.5 & 1.0 & 1 & 1 & 1 & 2 & 6 \\
\hline Retained components & 6 & 2.0 & 1.1 & 1 & 1 & 2 & 3 & 3 \\
\hline $\begin{array}{c}\text { Placenta accreta / } \\
\text { percreta / increta }\end{array}$ & 15 & 6.6 & 1.2 & 5 & 6 & 6 & 8 & 8 \\
\hline Genital Tract Trauma & 60 & 2.6 & 2.4 & 0 & 1 & 2 & 4 & 10 \\
\hline Coagulo-pathy & 15 & 1.8 & 2.3 & 0 & 0 & 1 & 2 & 6 \\
\hline
\end{tabular}

Average number of packed red cells (PRC) transfused (usage) for various indications of blood transfusion among the patients under study have been summarized in Table 1.

Out of 405 patients, $23.7 \%$ of the subjects received FFP transfusion and $16 \%$ platelet concentrates. Cryoprecipitate usage was minimal (3\%) among the study population.

TABLE - 2 USAGE OF FRESH FROZEN PLASMA, PLATELET CONCENTRATE AND CRYOPRECIPITATE FOR VARIOUS INDICATIONS RELATED TO OBSTETRIC HEMORRHAGE

\begin{tabular}{|c|c|c|c|}
\hline Usage per indication & $\begin{array}{c}\text { Pc } \\
\text { (units) }\end{array}$ & $\begin{array}{c}\text { Ffp } \\
\text { (units) }\end{array}$ & Cryo (units) \\
\cline { 2 - 4 } & Mean \pm sd & Mean \pm sd & Mean \pm sd \\
\hline Abruption & $0.6 \pm 1.6$ & $0.9 \pm 1.6$ & $0.2 \pm 0.6$ \\
\hline Atonicity & $0.6 \pm 1.4$ & $0.5 \pm 1.5$ & 0 \\
\hline $\begin{array}{c}\text { Placenta accreta } \\
\text { /percreta/ increta }\end{array}$ & $3.0 \pm 1.7$ & $4.6 \pm 1.9$ & 0 \\
\hline GT Trauma & $0.8 \pm 1.7$ & $1.7 \pm 3.0$ & 0 \\
\hline Coagulo-pathy & $2.8 \pm 3.8$ & $2.2 \pm 1.7$ & $0.8 \pm 1.7$ \\
\hline
\end{tabular}

Usage of platelet concentrate (PC), fresh frozen plasma (FFP) and cryoprecipitate units for various indications of blood transfusion have been shown in Table 2. Indications for blood component transfusion were analyzed, as depicted in Figure 1.

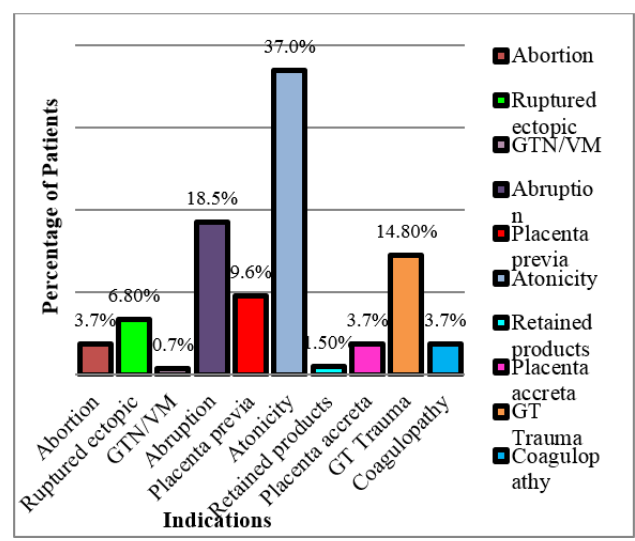

Figure 1:Various indications for transfusion of blood components in obstetric hemorrhage

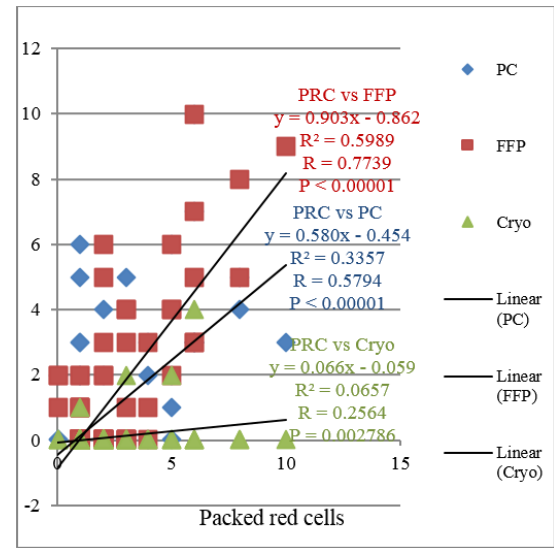

Figure 2: Relationship of packed red cells with platelet concentrate, fresh frozen plasma and cryoprecipitate used in the management of obstetric hemorrhage
TABLE - 3 RELATIONSHIP BETWEEN THE BLOOD COMPONENTS USED IN OBSTETRIC HEMORRHAGE MANAGEMENT

\begin{tabular}{|c|c|c|c|}
\hline Parameters & Pearson's R value & $\mathbf{R}^{2}$ value & P - value* \\
\hline PRC-PC & 0.5794 & 0.3357 & $<0.00001(\mathrm{HS})^{\#}$ \\
\hline PRC-FFP & 0.7739 & 0.5989 & $<0.00001(\mathrm{HS})^{\#}$ \\
\hline PRC-Cryo & 0.2564 & 0.0657 & $0.002786(\mathrm{HS})^{\#}$ \\
\hline
\end{tabular}

*Pearson's correlation test applied;

$\mathrm{R}=$ Pearson's Correlation Coefficient;

$\mathrm{R}^{2}=$ Coefficient of Determination:

$\mathrm{N}=403$; Degree of freedom 132;

${ }^{\#} \mathrm{HS}=$ Highly Significant;

Level of significance at $\mathrm{P}<0.05$.

A strong positive correlation of PRC usage was observed with the number of units (usage) of PC, FFP and Cryoprecipitate units transfused to the patients with obstetric hemorrhage, as illustrated in Figure 2 and Table $3(\mathrm{P}<0.00001 ; \mathrm{P}<0.00001$ and $\mathrm{P}=0.002786$ respectively), which means high usage of PRC goes with high usage of PC, FFP and Cryoprecipitate units and vice versa.

\section{DISCUSSION}

Different studies across the world had reported the incidence of transfusion of blood or blood component in obstetric hemorrhage varied from 1.4-6.8\%. ${ }^{[3-9]}$ Incidence of transfusion of blood or components in the present analysis (4.02\%) was in agreement with the above results.

In the present study, among the transfused cases, $72.6 \%$ received packed red cells alone, $1.5 \%$ FFP alone and rest of the subjects $(25.9 \%)$ received combination of blood components. Likewise in a research carried out by Patel VP et $\mathrm{al}_{1}{ }^{[5]} 80 \%$ of the patients were reported to be transfused with packed red cells alone and $20 \%$ were transfused with a combination of blood components like PRC, FFP, and Cryoprecipitate. In another retrospective study conducted in a Japanese centre, $92 \%$ of women received packed red cells, $4 \%$ received combination of packed cells and platelets and remaining $4 \%$ received combination of packed cells, platelets and fresh frozen plasma. ${ }^{[10]}$

As shown in Table 1, in present study, patients with placenta accrete / percreta / increta had maximum number of (mean) transfusions with packed red cells (6.6 \pm 1 .2units) followed by vesicular mole (3.0 units) and traumatic injury to the genital tract during delivery $(2.6 \pm 2.4$ units). For placenta accrete, mean RBC usage was $10 \pm 9$ units in a study by Stotler $B$ et al. ${ }^{[11]}$ Nazli Hossain et a ${ }^{[9]}$ noticed that their patients had an average transfusion of two unit PRC (range 1-9).

In the present study, $23.7 \%$ of the patients received FFP while considering the usage of platelet only $16 \%$ received it. Cryoprecipitate usage was minimal (3\%) among the study population. In a study by Mrinalini Balki et al ${ }_{1}^{[12]}$ they noticed that $42.3 \%$ were transfused with FFP, $18.2 \%$ with platelet concentrates and only $9.6 \%$ with cryoprecipitate.

The present analysis described (Table 2) maximum mean usages of platelet concentrate and fresh frozen plasma were for placenta accreta / percreta / increta $(3.0 \pm 1.7$ and $4.6 \pm 1.9$ units of PC and FFP respectively) followed by coagulopathy (2.8 \pm 3.8 and $2.2 \pm 1.7$ units of $\mathrm{PC}$ and FFP respectively) while cryoprecipitate was observed to be transfused in cases with coagulopathy $(0.8 \pm 1.7$ units) and abruptio placenta $(0.2 \pm 0.6$ units). Nazli Hossain et $\mathrm{al}^{[9]}$ observed that their patients received at least 1 unit of FFP (range 1-8) for the treatment of obstetric hemorrhage.

Most common indication for blood/blood component transfusions in our study was atonicity of the uterus (37\%), 
followed by abruption (18.5\%) and genital tract trauma during delivery(14.8\%). Other causes were placenta previa $(9.6 \%)$, ruptured ectopic (6.7\%), placenta accrete $(3.7 \%)$, coagulopathy $(3.7 \%)$, retained components of conception (1.5\%) and vesicular mole(0.7\%) (Figure 1).

As in other studies our study also pointed out that uterine atony $(36 \%)$ was the most common indication for blood transfusion. ${ }^{[5,12]}$ In a research conducted by Shigetaka Matsunaga et $a{ }_{1}{ }^{[10]}$ it was observed that uterine atony $(25.9 \%)$ was the most common indication for blood transfusion in obstetric hemorrhage followed by genital tract trauma including uterine rupture/injury (23.2\%), placental abruption (21.8\%), placenta previa (13.6\%), placenta previa with acreta / increta / percreta $(5.9 \%)$, uterine inversion (2.3\%), HELLP syndrome (6.8\%) and amniotic fluid embolism (0.5\%).

Mrinalini Balki et al ${ }^{[12]}$ reported atonicity $(21,80 \%)$ as the most common indication followed by bleeding due to retained components of conception (RPOC) $(2 ; 8 \%)$, extensive vaginal lacerations-related bleeding $(2 ; 8 \%)$ and abruptio placenta $(4 \%)$.

A strong positive correlation of PRC usage was observed with the number of units (usage) of PC, FFP and Cryoprecipitate units transfused to the patients with obstetric hemorrhage. In accordance with the present study, Shigetaka Matsunaga et $\mathrm{al}^{[10]}$ noticed a significant positive correlation $(P<0.001)$ between the volume of PRC transfused and that of FFP.

\section{CONCLUSION}

The present study concludes that incidence of transfusion of blood components in the present analysis was $4.02 \%$, the most common indication for transfusion of blood components being atonicity of the uterus (37\%), followed by abruption (18.5\%) and genital tract trauma (14.8\%) during delivery.

Maximum mean usages of packed red cells (6.6 \pm 1.2 units), platelet concentrate $(3.0 \pm 1.7)$ and fresh frozen plasma (4.6 \pm 1.9 units) were for placenta accreta / percreta / increta. There were only two indications for cryoprecipitate transfusions, i.e., coagulopathy and abruption placenta.

There is a strong positive association of PRC usage with the number of units (mean usage) of PC, FFP and Cryoprecipitate units transfused to the patients with obstetric hemorrhage $(\mathrm{P}<$ $0.00001 ; \mathrm{P}<0.00001$ and $\mathrm{P}=0.002786$ respectively), irrespective of underlying obstetric disorders.

\section{ACKNOWLEDGEMENT}

Authors wish to thank Dr. Shailendra Vashistha (MBBS, MD IHBT), Senior Demonstrator, Department of IH\&TM, S.P. Medical College, Bikaner and VAssist Research (www.thevassist.com) for their contribution in preparing the manuscript.

\section{REFERENCES:}

[1] Trends In Maternal Mortality 1990-2013: Estimates by WHO, UNICEF, UNFPA, The world bank and the United Nations Population Division.

[2] McLintock C., and James A. H. (2011), "Obstetric hemorrhage." Journal of Thrombsis and Haemostasis, 9, 1441-1451.

[3] Basu J.K., Hartford L., Nzama N., Dayal C., Naidoo B., Chuene M., and et al. (2012), "The use of blood transfusions in the obstetric unit of an academic hospital in South Africa-Brief reports." South African Journal of Epidemiology and Infections, 27, 1, 34-36.

[4] Parker J., Thompson J., and Stanworth S. (2009), "A retrospective one-year single-centre survey of obstetric red cell transfusions." International Journal of Obstetrics and Anesthesia, 18, 4, 309-313.

[5] Patel V.P., Patel R.V., Shah P.T., and Patel C.K. (2014), "Study of role of blood transfusion in obstetric emergencies." International Journal of Reproduction and Contraception in Obstetrics and Gynecology, 3, 1002-1005.

[6] Madhusudan D., and Vanamail P. (2013), "Blood loss and risk of blood transfusion in patients undergoing caesarean section." International Journal of Biomedical Advance Research, 4, 6, 425-429.

[7] Pandya J.M., Pandya M., and Patel M. (2015), "Role of blood transfusion in obstetrics." International Journal of Scientific Research, 4, 5, 3-6.

[8] Jou H.J., Hung H.W., Yan Y.H., and Wu S.C. (2012), "Risk factors for blood transfusion in singleton pregnancy deliveries in Taiwan." International
Journal of Gynaecology and Obstetrics, 117, 2, 124-127.

[9] Hossain N., Shah T., Khan N., Shah N., and Khan N.H. (2011), "Transfusion of blood and blood component therapy for postpartum haemorrhage at a tertiary referral center." Journal of Pakistan Medicine Association, 61, 343-345.

[10] Matsunaga S., Seki H., Ono Y., and et al. (2012), "A retrospective analysis of transfusion management for obstetric hemorrhage in a Japanese obstetric center." ISRN Obstetrics and Gynecology, 2012, 854064, 1-8.

[11] Stotler B., Padmanabhan A., Devine P., Wright J., Spitalnik S.L., and Schwartz J. (2011), "Transfusion requirements in obstetric patients with placenta accreta." Transfusion, 51, 2627-2633.

[12] Balki M., Dhumne S., Kasodekar S., Seaward G., Carvalho J.C.A. (2008), "Blood transfusion for primary postpartum hemorrhage: A tertiary care hospital review." Journal of Obstetrics and Gynaecology Canada, 30, 11, 1002-1007. 